\title{
The impact of multimorbidity patterns on health-related quality of life in the general population: results of the Belgian Health Interview Survey
}

\author{
Lisa Van Wilder ${ }^{1}$. . Brecht Devleesschauwer ${ }^{2,3}$. Els Clays ${ }^{1}$. Stefanie De Buyser ${ }^{4}$. Johan Van der Heyden ${ }^{2}$. \\ Rana Charafeddine ${ }^{2}$. Pauline Boeckxstaens ${ }^{1}$. Dirk De Bacquer ${ }^{1}$. Sophie Vandepitte ${ }^{1}$. Delphine De Smedt ${ }^{1}$
}

Accepted: 9 July 2021 / Published online: 23 August 2021

(c) The Author(s) 2021

\begin{abstract}
Background Chronic diseases and multimorbidity are a major cause of disease burden-for patients, caregivers, and society. Little is known however about potential interaction effects between specific disease combinations. Besides an additive effect, the presence of multiple conditions could also act synergistically or antagonistically regarding the impact on patients' health-related quality of life (HRQoL). The aim was to estimate the impact of coexisting chronic diseases on HRQoL of the adult general Belgian population.

Methods The Belgian Health Interview Survey 2018 provided data on self-reported chronic conditions and HRQoL (EQ$5 \mathrm{D}-5 \mathrm{~L}$ ) for a nationally representative sample. Linear mixed models were used to analyze two-way and three-way interactions of disease combinations on HRQoL.

Results Multimorbidity had a prevalence of $46.7 \%$ ( $\geq 2$ conditions) and $29.7 \%$ ( $\geq 3$ conditions). HRQoL decreased considerably with the presence of multiple chronic diseases. 14 out of 41 dyad combinations and 5 out of 13 triad combinations showed significant interactions, with a dominant presence of negative/synergistic effects. Positive/antagonistic effects were found in more subjective chronic diseases such as depression and chronic fatigue. Conditions appearing the most frequently in significant disease pair interactions were dorsopathies, respiratory diseases, and arthropathies.

Conclusions Diverse multimorbidity patterns, both dyads and triads, were synergistically or antagonistically associated with lower HRQoL. Tackling the burden of multimorbidity is needed, especially because most disease combinations affect each other synergistically, resulting in a greater reduction in HRQoL. Further knowledge about those multimorbidity patterns with a greater impact on HRQoL is needed to better understand disease burden beyond mortality and morbidity data.
\end{abstract}

Keywords Health-related quality of life $\cdot$ Multimorbidity $\cdot$ Chronic disease $\cdot$ EQ-5D

\section{Abbreviations \\ BHIS Belgian Health Interview Survey \\ DALY Disability-adjusted life years}

Lisa Van Wilder

lisa.vanwilder@ugent.be

1 Department of Public Health and Primary Care, Ghent University, University Hospital, Corneel Heymanslaan 10 4K3, 9000 Ghent, Belgium

2 Department of Epidemiology and Public Health, Sciensano, Brussels, Belgium

3 Department of Veterinary Public Health and Food Safety, Ghent University, Merelbeke, Belgium

4 Biostatistics Unit, Department of Public Health and Primary Care, Ghent University, Ghent, Belgium
EQ-5D-5L Five-level EuroQol five-dimensional questionnaire

HRQoL Health-related quality of life

ICD-10 International Classification of Diseases, 10th revision

QALY Quality-adjusted life year

\section{Introduction}

Chronic diseases are highly prevalent and responsible for $73 \%$ of all deaths globally [1,2]. Moreover, about half of the patients with a chronic disease suffer from multimorbidity, defined as the co-occurrence of multiple chronic conditions in a given individual [3]. Chronic diseases and in particular multimorbidity are a major cause of disease 
burden-for patients, caregivers, and society at large [4, 5]. Mortality measures alone are inadequate to capture the full impact of chronic diseases [6]. Hence, the interest into patients' health-related quality of life (HRQoL) measures is emerging. HRQoL captures individuals' self-perceived impact of a medical condition, its symptoms, and treatment referring to physical, mental, and social well-being, compared to what they believe to be ideal [5, 7]. Evidence shows a disease-associated loss in HRQoL, with HRQoL being an important predictor of morbidity and mortality $[8,9]$.

HRQoL loss in single chronic diseases has already been explored in several studies, however, the impact of combinations of diseases is understudied [1, 10-13]. Little is known about the interaction effect between different diseases on HRQoL. Besides an additive effect, multiple conditions could also act synergistically or antagonistically to impact HRQoL [14]. Previous research suggests synergetic effects between combinations of physical and mental conditions, however, in depth knowledge about the effect of specific pairs is lacking [15-17]. Given that multimorbidity affects an increasing number of people, knowledge on how this impacts self-perceived health is of major importance [18, 19].

The Belgian Health Interview Survey (BHIS) collected data on chronic diseases and HRQoL in a large representative sample of the general Belgian population [20,21]. These data allow for gaining a better understanding of potential interaction effects between specific chronic diseases, which could be of major interest to researchers, clinicians, and policy makers worldwide. This study aims to estimate how the co-occurrence of different chronic diseases can impact a person's HRQoL.

\section{Methods}

\section{Belgian Health Interview Survey}

Data from the BHIS 2018 were used [22]. BHIS is a crosssectional household survey that includes a representative sample of the Belgian population through multistage stratified sampling, involving a geographical stratification, a selection of clusters within each stratum, a selection of households within each cluster, and a selection of individuals within each household. In 2018, 11,611 individuals were interviewed with a response rate of $57 \%$ at the household level. Data collection were undertaken using face-to-face interviews (to obtain socio-demographic information) and supplemented with a self-administered questionnaire (to obtain HRQoL data). Details on methodology of the BHIS can be found elsewhere [23].

\section{Measures}

Prevalence of chronic diseases was self-reported, based on the following question: 'Have you had one of the following disease or condition in the past 12 months?'. Participants indicated on a list of 38 diseases whether they had suffered from a certain disease with the responses 'yes' or 'no'. The list also included chronic conditions (e.g. hypertension), consequences of chronic disease (e.g. hip fracture), and acute diseases with chronic consequences (e.g. stroke). The 38 chronic conditions were mapped into 23 chronic diseases or disease groups because many conditions are affecting the same body system. The mapping was based on the ICD-10 and a multimorbidity questionnaire (Table 1) [24, 25].

To date, consensus on the definition of multimorbidity is still lacking. The definition of $\geq 2$ chronic diseases is under discussion, especially when highly prevalent conditions (e.g. hypertension) are included because these may result in high prevalence rates even if there is a lesser impact on patients' symptoms, functional status, and HRQoL [26]. This study therefore used both cutoff values of $\geq 2$ and $\geq 3$ concurrent diseases to define multimorbidity.

HRQoL was measured using the EQ-5D-5L, the most widely used preference-based instrument for measuring HRQoL [21] and recommended by Belgian guidelines for economic evaluations in health care [27]. The EQ-5D-5L includes a descriptive system consisting of five dimensions: mobility, self-care, usual activities, pain/discomfort, and anxiety/depression. Each dimension has five response categories (no problems, slight problems, moderate problems, severe problems, and extreme problems/unable to), from which a single index value or utility score can be calculated ranging between 0 (death) and 1 (perfect health). Negative values can also be generated for health states perceived worse than death. Converting the dimension scores into a single index value requires a country-specific algorithm based on population-level preferences for different health states. In Belgium, however, such an algorithm is so far only available for the EQ-5D-3L encompassing only three answering possibilities [28]. A cross-walk function was therefore used to map the EQ-5D-5L health states to EQ-5D-3L health states, resulting in index values ranging from -0.158 to $1[29,30]$. The EQ-VAS, measuring respondents' self-rated health on a 0-100 scale, was not included in the BHIS 2018.

The following socio-demographic data were used: age (15 to 101 years), sex (male, female), educational attainment (no diploma, lower education, lower secondary education, higher secondary education, post-secondary education, higher education, doctoral degree), civil 
Table 1 Mapping of the chronic diseases according to the MM-21 and ICD-10

\begin{tabular}{|c|c|}
\hline BHIS 2018 (38 chronic diseases) & MM-21/ICD-10 (23 chronic diseases) \\
\hline Allergy & Allergy $(T 78.4, \mathrm{~J} 30.1)$ \\
\hline Hip fracture & Hip fracture (S70-S79) \\
\hline Cancer & Cancer (C00-D49) \\
\hline Chronic fatigue & Chronic fatigue (R53) \\
\hline Chronic skin disease & Chronic skin disease (L80-L9) \\
\hline Cirrhosis of the liver/liver dysfunction & Cirrhosis of the liver (K70-K77) \\
\hline Disorder of the larger or the small bowel & Bowel disorder (K50-K52, K57, K58) \\
\hline Gallstones of inflammation of the gallbladder & Gallstones (K80-K87) \\
\hline Osteoporosis & Osteoporosis (M81) \\
\hline Serious disease of the kidney & Kidney disease (N18, N19) \\
\hline Serious gloom or depression & Depression (F33, F40, F41) \\
\hline Stomach ulcer & Stomach disorder (K21, K25.7, K29.5) \\
\hline Stroke (or consequences) & Stroke (G45, I60-169) \\
\hline Thyroid problems & Thyroid problems (E00-E07) \\
\hline $\begin{array}{l}\text { Hypertension } \\
\text { High cholesterol level in blood }\end{array}$ & Hypertension/high cholesterol (I10-I15, E78) \\
\hline $\begin{array}{l}\text { Low back disorder } \\
\text { Neck disorder }\end{array}$ & $\begin{array}{l}\text { Dorsopathies (M40-M54, M60-M63, M65-M68, } \\
\text { M70-M79) }\end{array}$ \\
\hline $\begin{array}{l}\text { Rheumatoid arthritis } \\
\text { Osteoarthritis/arthrosis }\end{array}$ & Arthropathies (M05.9, M13.0, M13.9, M15-M19) \\
\hline $\begin{array}{l}\text { Asthma } \\
\text { Chronic bronchitis/COPD/emphysema }\end{array}$ & Respiratory disease (J40-J47) \\
\hline $\begin{array}{l}\text { Diabetes } \\
\text { Diabetic retinopathy }\end{array}$ & Diabetes (E10-E14) \\
\hline $\begin{array}{l}\text { Epilepsy } \\
\text { Parkinson's disease } \\
\text { Severe headache (e.g. migraine) }\end{array}$ & Neurological disorder (G40, G20,G43) \\
\hline $\begin{array}{l}\text { Macular degeneration } \\
\text { Glaucoma } \\
\text { Cataract }\end{array}$ & Eye disease $(\mathrm{H} 35, \mathrm{H} 40-\mathrm{H} 42, \mathrm{H} 25, \mathrm{H} 26, \mathrm{H} 28)$ \\
\hline $\begin{array}{l}\text { Myocardial infarction } \\
\text { Narrowing of blood vessels in belly or legs } \\
\text { Serious heart disease } \\
\text { Coronary heart disease }\end{array}$ & Cardiovascular disease $(120-125,148,170-179)$ \\
\hline $\begin{array}{l}\text { Urinary incontinence } \\
\text { Stones in the kidney } \\
\text { Chronic cystitis } \\
\text { Prostate problems }\end{array}$ & $\begin{array}{l}\text { Genitourinary problems (N03, N11, N18, N20- } \\
\text { N23, N25-N29, N30-N39, N40-N51) }\end{array}$ \\
\hline
\end{tabular}


status (single, married or legally cohabiting, widow(er), divorced), and region (Brussels, Flanders, Wallonia). Socio-economic status was based on the highest level of education of the household and classified into low (lower secondary education or less), intermediate (higher secondary education), and high (higher education). Only participants who completed the EQ-5D-5L were included.

\section{Statistical analyses}

Statistics were undertaken using IBM SPSS statistical software (version 26.0). The design effects of the survey were taken into account to deal with the complex design of the BHIS [23], resulting in representativeness for the total population, at national, regional, and provincial level.

A contingency table in matrix form was constructed to determine patterns of combinations of diseases. To increase robustness, only combinations occurring $\geq 2.5 \%$ (arbitrary cut-off) in the population were considered here.

We fitted linear mixed models to analyze two-way and three-way interaction effects (i.e. effect modifications) of disease combinations on HRQoL. The EQ-5D-5L index score was the dependent variable in all models. The individual diseases were included as fixed effects. Each model also contained a two-way or three-way interaction term plus all underlying interactions for the dyad and triad combinations, respectively. The following design effects of the survey were taken into account: clustering at household level as random effect (random intercept for household), regional stratification as fixed factor, and survey weights as weighting. Normality of the residuals was assessed by Q-Q plot. We relied on the central limit theorem, given our large sample size. Significance of the interaction between two comorbidities indicates that the effect of one comorbidity is different in the presence or absence of the other comorbidity. A negative interaction (i.e. synergistic effect) shows that the combined effect of two comorbidities was associated with an estimated mean decrease in HRQoL that is higher (stronger/more pronounced) than expected based on the additive effect of the comorbidities separately. Conversely, a positive interaction (i.e. antagonistic effect) indicates that the combined effect of two comorbidities was associated with an estimated mean decrease in HRQoL that is less than expected based on the additive effect of each of them individually. It is important to highlight that effect modification is bidirectional meaning that each disease simultaneously influences, and is influenced by, the other disease. Estimated marginal mean HRQoL scores for each disease combination were calculated from the final model. The regression models were not adjusted for several covariates (e.g. age, sex, educational attainment), because the aim was not to find the model with the most ideal goodness-of-fit, but rather to depict the actual situation. P-values have not been adjusted for multiplicity.
Statistical significance was set at $P<0.05$, trends towards significance $(P<0.1)$ were also presented.

\section{Results}

\section{Sample characteristics}

The EQ-5D-5L was completed by $85 \%$ of participants $(n=7,509)$. Descriptive statistics are outlined in Table 2. The mean age was 48.6 years, and slightly more than half were women (51.6\%). About half of the participants had a high socioeconomic status (50.8\%), whilst $16.8 \%$ had a low socioeconomic status. Approximately $30 \%$ had no chronic disease and $23.4 \%$ had one chronic disease. Multimorbidity occurred in $46.7 \%$ ( $\geq 2$ conditions) and $29.7 \%$ ( $\geq 3$ conditions) of the participants. Multimorbidity was more prevalent in women and increased with age and lower socioeconomic status. Females, older persons, and persons with lower socioeconomic status had lower HRQoL. Moreover, HRQoL decreased considerably with the presence of multiple chronic diseases. Participants with $\geq 3$ chronic diseases (0.65) reported a considerably lower HRQoL score compared to participants with two chronic diseases $(0.79)$ or with one chronic disease (0.85). Participants without chronic disease reported the highest HRQoL score (0.90).

\section{Single chronic diseases}

The three most common chronic diseases were dorsopathies (31.4\%), hypertension/high cholesterol (28.6\%), and arthropathies (22\%) (Table 3). On the other hand, stroke and hip fracture had a prevalence lower than $1 \%$. HRQoL scores varied between diseases. The highest HRQoL score was reported in persons with allergy $(0.75)$, followed by hypertension/high cholesterol (0.73), and thyroid problems (0.71). The lowest HRQoL score was reported in persons with depression (0.53), followed by stroke $(0.54)$, and chronic fatigue (0.58).

\section{Dyads of chronic diseases}

The prevalence matrix generated 41 dyad combinations with a prevalence $\geq 2.5 \%$ (Online Appendix 1). The most prevalent dyads were arthropathies + dorsopathies (14.6\%), hypertension/high cholesterol + dorsopathies (12.8\%), and hypertension/high cholesterol + arthropathies (11.8\%). Figure 1 and Fig. 2 summarize the interaction effects and estimated mean HRQoL scores for the 41 dyads respectively.

The highest HRQoL score was reported in persons with allergy + respiratory disease $(0.69)$ and hypertension/high cholesterol + allergy (0.69). The lowest HRQoL score was 


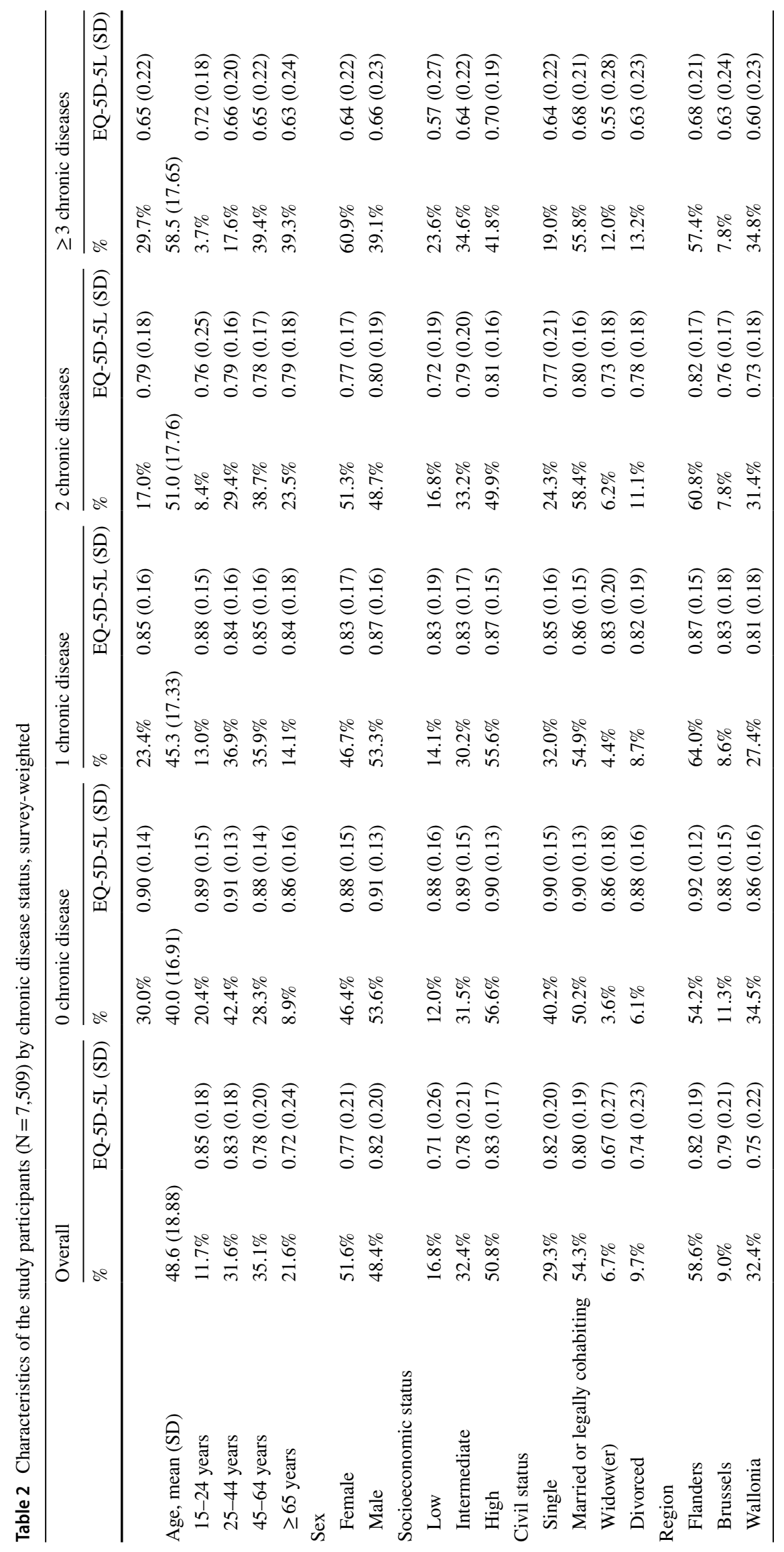


Table 3 Prevalence and estimated mean health-related quality of life (HRQoL) score for single chronic diseases

\begin{tabular}{lclll}
\hline & Total $(\%)$ & Women $(\%)$ & Mean age & Est. mean HRQoL score \\
\hline Hip fracture & 0.5 & 58.3 & 70.7 & $0.61(0.54-0.68)$ \\
Stroke & 0.6 & 27.4 & 69.6 & $0.54(0.48-0.60)$ \\
Cirrhosis of the liver & 1.0 & 62.8 & 60.1 & $0.64(0.60-0.69)$ \\
Gallstones & 1.0 & 84.6 & 54.2 & $0.69(0.64-0.73)$ \\
Kidney disease & 1.0 & 68.0 & 55.6 & $0.70(0.66-0.74)$ \\
Cancer & 2.2 & 60.1 & 61.5 & $0.65(0.62-0.68)$ \\
Osteoporosis & 3.3 & 89.2 & 69.0 & $0.61(0.59-0.64)$ \\
Stomach ulcer & 3.4 & 64.7 & 51.4 & $0.66(0.63-0.68)$ \\
Chronic skin disease & 4.0 & 58.5 & 49.4 & $0.68(0.65-0.70)$ \\
Eye disease & 4.4 & 57.2 & 70.9 & $0.67(0.65-0.69)$ \\
Bowel disorder & 4.7 & 68.8 & 55.2 & $0.63(0.61-0.66)$ \\
Cardiovascular disease & 5.8 & 46.8 & 66.8 & $0.64(0.62-0.66)$ \\
Diabetes & 6.0 & 48.2 & 64.7 & $0.67(0.65-0.69)$ \\
Thyroid problems & 7.0 & 84.2 & 56.7 & $0.71(0.69-0.73)$ \\
Depression & 7.4 & 63.3 & 50.2 & $0.53(0.52-0.55)$ \\
Chronic fatigue & 8.3 & 63.5 & 49.7 & $0.58(0.57-0.60)$ \\
Respiratory disease & 8.4 & 58.1 & 52.3 & $0.68(0.66-0.69)$ \\
Neurological disorder & 11.5 & 65.4 & 44.6 & $0.69(0.68-0.71)$ \\
Genitourinary problems & 15.7 & 52.2 & 63.4 & $0.64(0.62-0.65)$ \\
Allergy & 20.0 & 56.4 & 45.6 & $0.75(0.74-0.76)$ \\
Arthropathies & 22.0 & 60.7 & 62.2 & $0.65(0.64-0.66)$ \\
Hypertension/high cholesterol & 28.6 & 51.6 & 61.2 & $0.73(0.72-0.73)$ \\
Dorsopathies & 31.4 & 56.0 & 53.5 & $0.67(0.67-0.68)$ \\
\hline
\end{tabular}

reported in persons with depression + arthropathies $(0.44)$ and depression + genitourinary problems (0.44).

Based on our data, effect modification was observed for a minority of combinations (14 out of 41 pairs) and showed a mixed pattern: some interactions were negative/synergistic, some interactions were positive/antagonistic. The condition appearing the most frequently in significant disease pair interactions was dorsopathies, followed by respiratory disease and arthropathies.

The majority of disease pairs ( 9 out of 14 pairs) showed negative/synergistic interactions. The strongest negative/synergistic associations were found for dorsopathies + respiratory disease $(P<0.01)$, hypertension/high cholesterol + neurological disorder $(P<0.01)$, arthropathies + thyroid problems $(P<0.01)$, and genitourinary problems + respiratory disease $(P<0.01)$. The estimated mean decrease in HRQoL is also stronger in the presence of the following coexisting conditions: arthropathies + respiratory disease $(P<0.05)$, dorsopathies + cardiovascular disorder $(P<0.05)$, dorsopathies + thyroid problems $(P<0.05)$, hypertension/high cholesterol + depression $(P<0.1)$, and dorsopathies + genitourinary problems $(P<0.1)$.

The strongest positive/antagonistic association was observed for respiratory disease + allergy $(P<0.01)$. The estimated mean decrease in HRQoL is also smaller in the presence of the following coexisting conditions: depression + dorsopathies $(P<0.05)$, arthropathies + dorsopathies $(P<0.1)$, chronic fatigue + neurological disorder $(P<0.1)$, depression + chronic fatigue $(P<0.1)$.

\section{Triads of chronic diseases}

Thirteen triad combinations with a prevalence $\geq 2.5 \%$ were observed. The most frequent triad combinations were hypertension/high cholesterol + arthropathies + dorsopathies (8.1\%), hypertension/high cholesterol + genitourinary problems + dorsopathies (5.1\%), and dorsopathies + arthropathies + genitourinary problems (4.9\%). Figure 3 and Fig. 4 summarize the interaction effects and estimated mean HRQoL scores for the thirteen triads respectively.

The highest HRQoL score was reported in persons with allergy + hypertension/high cholesterol + dorsopathies (0.62). The lowest HRQoL score was reported in persons with depression + genitourinary problems + dorsopathies (0.37).

Five triad combinations showed significant interactions $(P<0.01)$. Negative/synergistic interactions were found for genitourinary problems + chronic fatigue + dorsopathies, genitourinary problems + depression + dorsopathies, genitourinary problems + allergy + dorsopathies, and hypertension/ high cholesterol + arthropathies + dorsopathies. A positive/ 

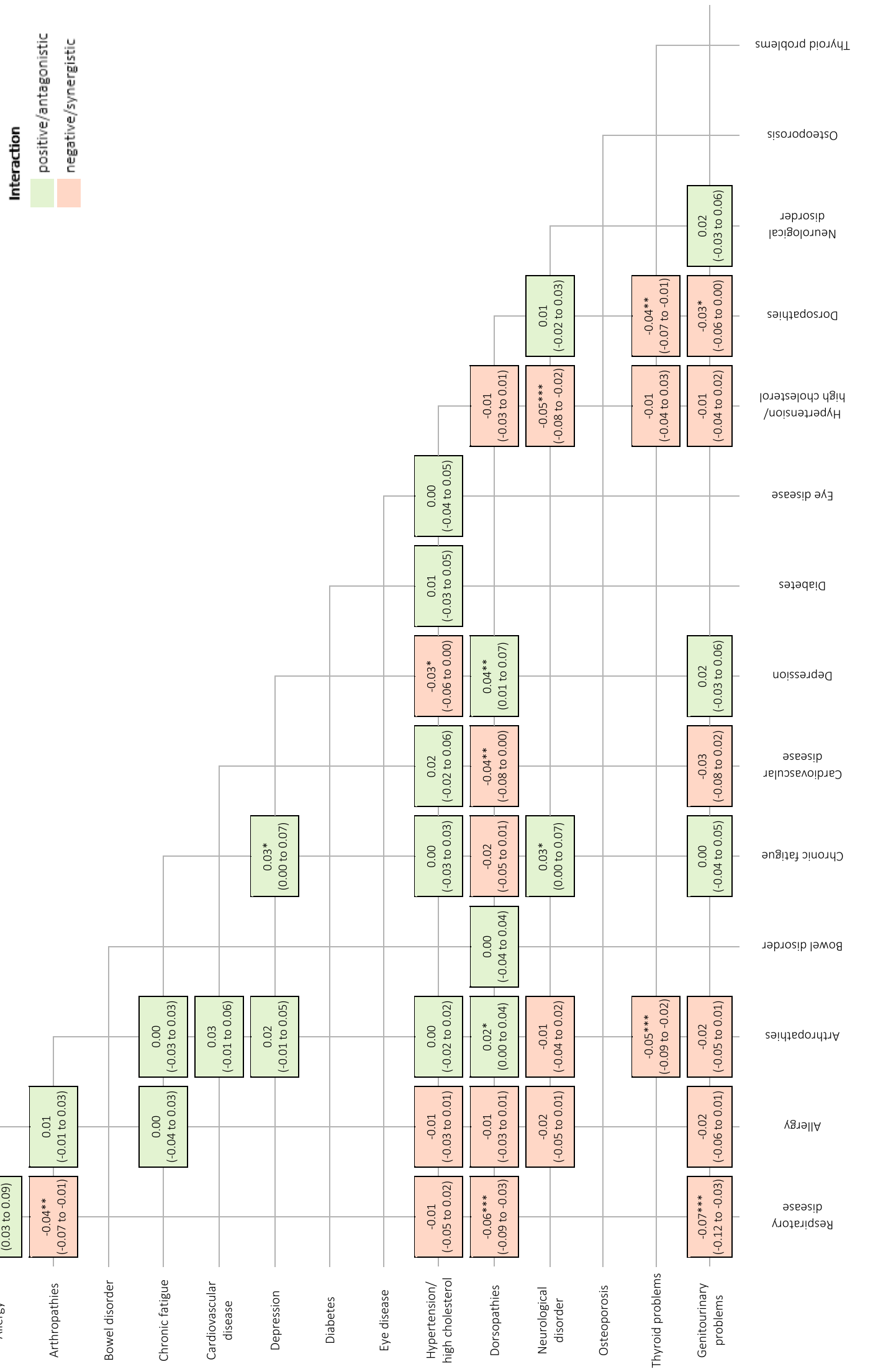

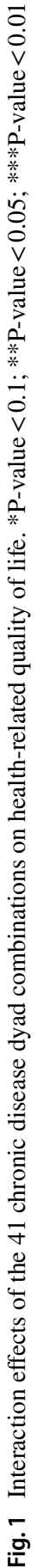




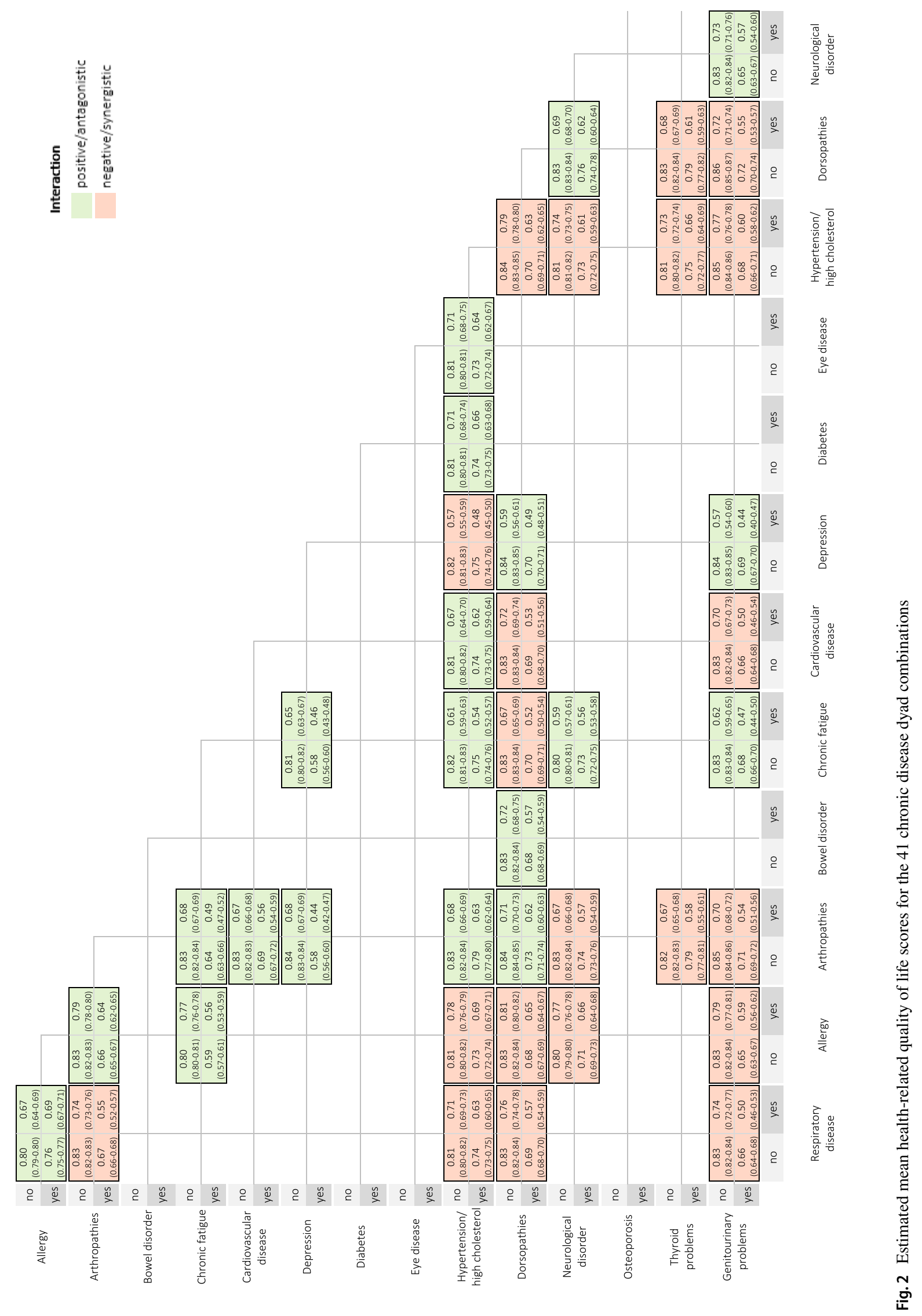




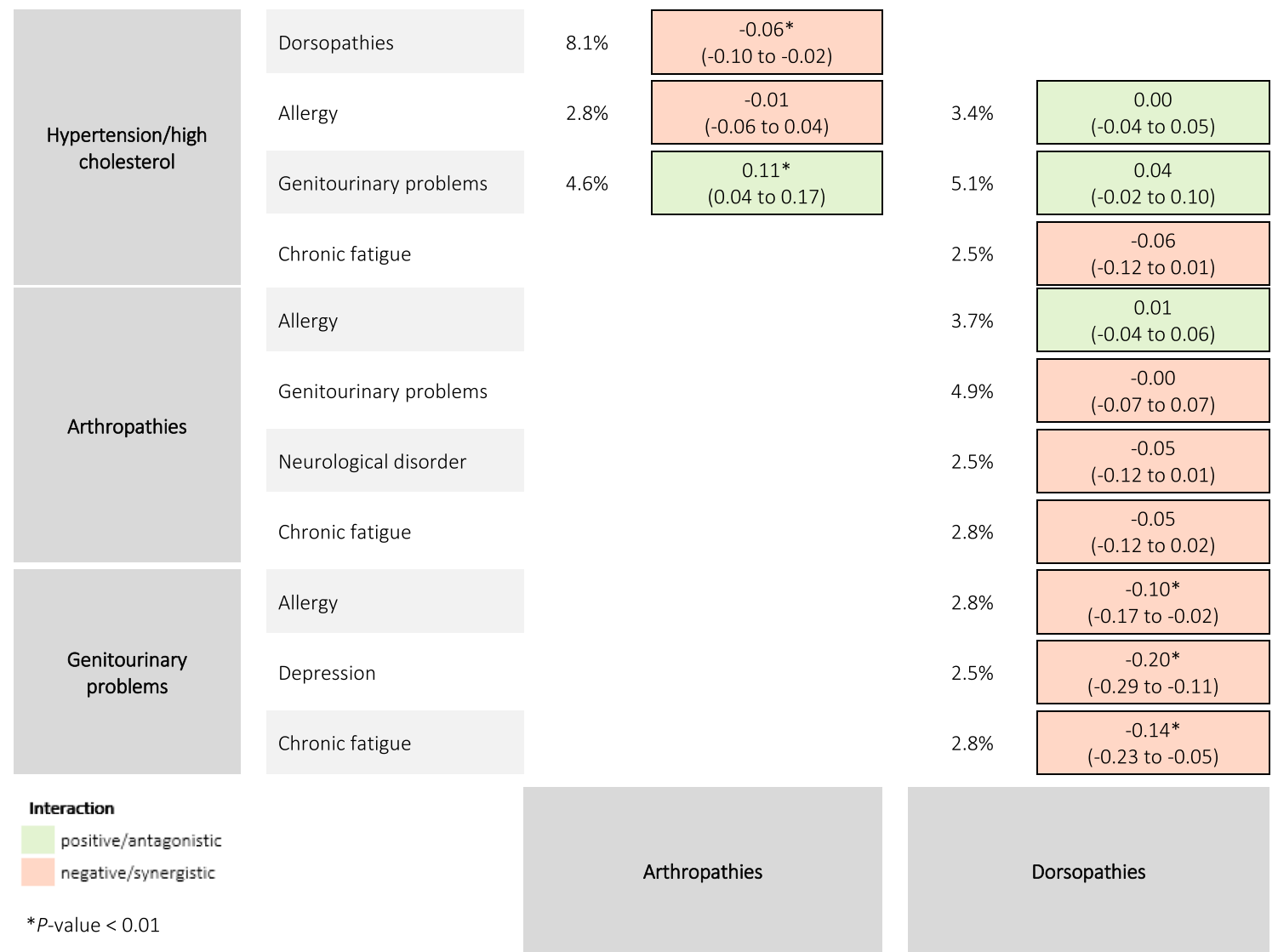

Fig. 3 Prevalence and interaction effects of the 13 chronic disease triad combinations on health-related quality of life

antagonistic interaction was found for hypertension/high cholesterol + genitourinary problems + arthropathies.

\section{Discussion}

This study estimated the impact of multimorbidity patterns on HRQoL in a representative sample of the Belgian population. Interaction effects of coexisting conditions were estimated based on self-reported data across 23 chronic diseases or disease groups. With these results, we aimed at meeting the rising demand from epidemiologists, clinicians, and policy makers for a better understanding of the burden of chronic diseases, in particular the clinical and societal impact of multimorbidity. In addition, health economists can use the results in their cost-effectiveness analysis supporting reimbursement decisions. The joint effects of disease combinations on HRQoL have been explored in several studies, however, interaction estimates for specific conditions with low prevalence rates measured by the EQ-5D-5L have not been previously investigated in such detail [14, 31-33]. Moreover, to the best of our knowledge, this study is the first to investigate interaction effects of triad disease combinations on HRQoL measured by the EQ-5D-5L.

Our results show that the estimated mean HRQoL is lower when a chronic disease is present compared to when it is absent. Chronically ill patients had lower HRQoL scores, ranging from 0.53 to 0.75 , compared to the reference value (0.84) from the Belgian general population in 2018 [34]. Indeed, a large body of evidence confirms the substantial reduction in HRQoL across chronic diseases [35].

Multimorbidity was highly prevalent, which may be attributed to the large number of chronic diseases included [36]. A review of prevalence studies identified estimates ranging between less than $5 \%$ to more than $95 \%$, often due to discrepancies in the operational definition and cut-off value used to define multimorbidity, which makes comparison across populations difficult $[26,36]$. More importantly, there is still no universally accepted definition for what constitutes to 'chronic' conditions in multimorbidity research. Hence, this study included all conditions assessed in the BHIS, even 


\begin{tabular}{|c|c|c|c|c|c|c|c|}
\hline & & & no & $0.85(0.85-0.86)$ & $0.72(0.70-0.74)$ & & \\
\hline & 10 & & yes & $0.73(0.72-0.75)$ & $0.65(0.63-0.66)$ & & \\
\hline & & tersupatines & no & $0.81(0.80-0.82)$ & $0.71(0.68-0.73)$ & & \\
\hline & yes & & yes & $0.71(0.69-0.73)$ & $0.59(0.57-0.60)$ & & \\
\hline & & & no & $0.84(0.83-0.85)$ & $0.68(0.67-0.70)$ & $0.84(0.84-0.85)$ & $0.71(0.69-0.72)$ \\
\hline & & & yes & $0.80(0.79-0.82)$ & $0.67(0.64-0.69)$ & $0.83(0.81-0.84)$ & $0.68(0.66-0.70)$ \\
\hline & & MIICISY & no & $0.79(0.78-0.80)$ & $0.64(0.62-0.65)$ & $0.79(0.78-0.80)$ & $0.64(0.63-0.66)$ \\
\hline Hypertension/ & & & yes & $0.76(0.73-0.78)$ & $0.61(0.58-0.63)$ & $0.76(0.74-0.79)$ & $0.62(0.59-0.64)$ \\
\hline high cholesterol & & & no & $0.86(0.85-0.87)$ & $0.74(0.71-0.76)$ & $0.87(0.86-0.88)$ & $0.75(0.73-0.77)$ \\
\hline & 10 & Genitourinary & yes & $0.75(0.72-0.77)$ & $0.54(0.51-0.58)$ & $0.75(0.73-0.78)$ & $0.59(0.56-0.62)$ \\
\hline & & problems & no & $0.82(0.80-0.83)$ & $0.67(0.65-0.69)$ & $0.82(0.81-0.84)$ & $0.67(0.65-0.69)$ \\
\hline & yes & & yes & $0.66(0.63-0.68)$ & $0.54(0.51-0.56)$ & $0.68(0.65-0.71)$ & $0.53(0.51-0.56)$ \\
\hline & & & no & & & $0.85(0.84-0.86)$ & $0.72(0.71-0.73)$ \\
\hline & 110 & & yes & & & $0.67(0.65-0.70)$ & $0.55(0.53-0.58)$ \\
\hline & & & no & & & $0.80(0.78-0.81)$ & $0.67(0.65-0.68)$ \\
\hline & yes & & yes & & & $0.66(0.63-0.70)$ & $0.48(0.46-0.51)$ \\
\hline & & & no & & & $0.85(0.84-0.86)$ & $0.73(0.72-0.75)$ \\
\hline & 110 & & yes & & & $0.83(0.81-0.84)$ & $0.70(0.68-0.72)$ \\
\hline & & & no & & & $0.72(0.70-0.73)$ & $0.62(0.61-0.63)$ \\
\hline & yes & & yes & & & $0.70(0.67-0.73)$ & $0.60(0.58-0.62)$ \\
\hline & & & no & & & $0.87(0.86-0.88)$ & $0.76(0.75-0.78)$ \\
\hline & 110 & Genitourinary & yes & & & $0.75(0.73-0.77)$ & $0.63(0.60-0.66)$ \\
\hline & & problems & no & & & $0.76(0.74-0.79)$ & $0.65(0.63-0.67)$ \\
\hline & yes & & yes & & & $0.62(0.58-0.66)$ & $0.50(0.47-0.52)$ \\
\hline 年 & & & no & & & $0.85(0.84-0.86)$ & $0.74(0.72-0.75)$ \\
\hline & 110 & 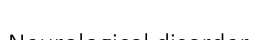 & yes & & & $0.78(0.76-0.79)$ & $0.68(0.65-0.70)$ \\
\hline & & The & no & & & $0.72(0.70-0.74)$ & $0.63(0.62-0.65)$ \\
\hline & yes & & yes & & & $0.66(0.61-0.71)$ & $0.54(0.51-0.56)$ \\
\hline & $\operatorname{mos}$ & & no & & & $0.85(0.84-0.86)$ & $0.75(0.74-0.76)$ \\
\hline & & Chronis fatiaus & yes & & & $0.69(0.67-0.72)$ & $0.58(0.56-0.61)$ \\
\hline & $=0$ & Ciliumili Iatigue & no & & & $0.73(0.71-0.74)$ & $0.65(0.64-0.66)$ \\
\hline & & & yes & & & $0.60(0.55-0.64)$ & $0.46(0.44-0.49)$ \\
\hline & & & no & & & $0.86(0.85-0.87)$ & $0.73(0.71-0.74)$ \\
\hline & & & yes & & & $0.83(0.81-0.85)$ & $0.71(0.68-0.73)$ \\
\hline & & Alletgy & no & & & $0.71(0.69-0.74)$ & $0.58(0.55-0.60)$ \\
\hline & & & yes & & & $0.74(0.69-0.78)$ & $0.51(0.48-0.54)$ \\
\hline & $n n^{2}$ & & no & & & $0.87(0.86-0.88)$ & $0.74(0.72-0.75)$ \\
\hline 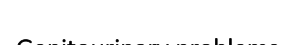 & no & Da & yes & & & $0.58(0.54-0.62)$ & $0.56(0.52-0.60)$ \\
\hline & sec & & no & & & $0.74(0.72-0.76)$ & $0.62(0.60-0.64)$ \\
\hline & yes & & yes & & & $0.58(0.52-0.63)$ & $0.37(0.34-0.41)$ \\
\hline & & & no & & & $0.86(0.85-0.87)$ & $0.74(0.73-0.75)$ \\
\hline & 110 & 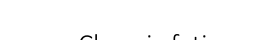 & yes & & & $0.66(0.62-0.70)$ & $0.57(0.54-0.61)$ \\
\hline & & Cilluiri iatigue & no & & & $0.73(0.71-0.75)$ & $0.62(0.59-0.64)$ \\
\hline & & & yes & & & $0.63(0.57-0.68)$ & $0.41(0.38-0.44)$ \\
\hline & & & & no & yes & no & yes \\
\hline
\end{tabular}

positive/antagonistic

negative/synergistic

Fig. 4 Estimated mean health-related quality of life scores for the 13 chronic disease triad combinations 
though some conditions are contentious (e.g. hip fracture, allergy) [37]. Moreover, the prevalence of multimorbidity is determined by the population studied (e.g. higher prevalence in older populations) and depends on the setting (e.g. higher prevalence in primary care than in the general population) [26, 36, 38]. Despite methodological variability, our multimorbidity pattern is more or less similar to other findings [17, 39, 40].

Disability-adjusted life year (DALY) is used as key metric to estimate overall disease burden [41]. At present, three comorbidity adjustment approaches exist within the burden of disease context, i.e. additive, multiplicative, and maximum approach [42]. However, these approaches ignore the probability that a combined effect can be higher than the sum of the independent condition effects [42]. Conversely, our results showed that synergistic effects were more common within multimorbidity patterns. Besides, we demonstrated novel synergistic effects. More specifically, we identified nine pairs with negative interaction effects on HRQoL, of which four were sufficiently large and precisely estimated. These results confirm the evidence that the impact of chronic diseases on HRQoL is not only reflected by the simple sum of the diseases [31-33, 43]. A possible mechanism for explaining these synergistic effects is that treatment for one condition could adversely affect another pre-existing condition, resulting in a greater reduction in HRQoL [44]. Moreover, coexisting conditions may affect different body systems and HRQoL dimensions, for example low back problems and depression [32]. Results of previous studies on the joint effect of diseases are heterogeneous. Synergetic interactions of combinations such as diabetes + cardiovascular disease, stroke + coronary disease or diabetes + hypertension were not observed in this study [31, 32, 45].

Our results also identified significant antagonistic interactions. It is remarkable that antagonistic interactions were found in more subjective diseases such as depression and chronic fatigue. A possible explanation for subtractive effects can be related to the concept of 'response shift', which reflects patients' adaptation to their new life circumstances as a result of changing health [46]. These adaptations may help to buffer the impact of a second medical condition, resulting in a smaller decrement in HRQoL than would otherwise be expected [47]. Another plausible explanation could be the healthy-responder effect, indicating that persons with, for example, more severe depression may be underrepresented, leading to higher HRQoL scores [47]. Moreover, several combinations (e.g. respiratory disease + allergy, chronic fatigue + depression) have similar symptoms and common aetiology, hence additional diagnosis has less impact on HRQoL [32]. However, the latter can also be attributed to 'response bias'; people may have indicated one condition under several other denominators because of unclear diagnosis, which results in double reporting. A final explanation is that pain relief medicines or antidepressants for one condition may have beneficial effects on other coexisting conditions.

Literature suggest that the effects of multimorbidity on HRQoL may be more complex than observed by pairwise interaction terms [31]. Nevertheless, estimations of threeway interactions are largely understudied due to insufficient observations and the difficult interpretation [31]. This study considered three-way combinations to fully capture higher order interactions. As a result, significant interactions were found for five triad combinations. Analogous to the results of the dyad combinations, we observed a dominant presence of synergistic effects. These results suggest that any additional condition is commonly associated with greater reduction in HRQoL. To date, there are no studies that have investigated the interaction between triad combinations on HRQoL, hence our results could not be compared with previous findings.

\section{Sensitivity analysis}

Recently, an EQ-5D-5L value set for Belgium has been developed [48]. As such, we performed a sensitivity analysis to assess the impact of the new value set on results and conclusions. The analysis showed that results systematically differed according to the value set used. The EQ$5 \mathrm{D}-5 \mathrm{~L}$ value set produces higher values overall and across all conditions included. These results are not unexpected because similar findings were found in other countries (e.g. England, The Netherlands, Spain) with higher utility values for the EQ-5D-5L value set compared to the crosswalk value set [49-51]. In addition, the new value set generates 12 additional significant interaction effects for dyad disease combinations (Online Appendix 2). In detail, four significant positive/antagonistic interactions have disappeared, 16 significant negative/synergistic interactions have been added. Moreover, mainly disease combinations with depression and chronic fatigue changed from positive/antagonistic interactions to negative/synergistic interactions, with stronger significance levels. In general, only disease combinations that fall within the same disease classification system (i.e. allergy + respiratory disease, hypertension/high cholesterol + cardiovascular disease) have an antagonistic relationship. As such, we can conclude that there will always be an synergistic/negative HRQoL effect, making multimorbidity even more important than initially thought. Possible reasons for the observed differences may be attributed to changes 
in for example population demographics, preferences over time, descriptive system of the EQ-5D, and valuation method used $[49,51]$. The magnitude of differences between value sets may however have important implications for decisionmaking as they can greatly impact estimates (e.g. QALYs) of health economic evaluations.

\section{Strengths and limitations}

This study has several major strengths. A first strength is that the BHIS data is based on a large, representative sample of the general population which strengthens external validity. A second strength is the availability of a Belgian value set for the EQ-5D-3L because guidelines recommend countryspecific value sets to estimate HRQoL more precisely within a country. Another strength is the large sample of morbidity across 38 long-term conditions, which allowed the assessment of interaction effects of coexisting conditions with low prevalence often not detectable in smaller studies [31, 52]. Nevertheless, grouping the 38 diseases into 23 disease groups may have masked potential interactions between diseases within larger disease groups, however, if synergistic or antagonistic effects were present, it is also expected to detect them across disease groups [17].

Some limitations should be considered. A first limitation is that the presence of chronic diseases was based on self-reports. Accurate self-reports require sufficient knowledge of participants to report on medical conditions. This is challenging because patients are often confused to distinguish between symptoms and the actual disease, and because some diseases are very subjective (e.g. chronic fatigue) [53]. In addition, it is possible that people indicate that they have several diseases because these conditions share homogeneous symptoms and common aetiology. Another important concern when using self-reports, especially over a 12 -month time period, is recall bias [54]. Self-reports are not as valid and reliable as medical records because respondents may underestimate/overestimate the prevalence of medical conditions and risk behaviours [55-59]. However, several studies found a high concordance between self-reports and medical records when measuring the prevalence of multimorbidity [60-64]. As well, self-reported data are the most appropriate alternative in the absence of objective diagnoses. Another limitation is the non-exhaustive list of chronic diseases included in the BHIS. This implies missing other important diseases such as Alzheimer's disease, which has previously been found to greatly impact HRQoL [65, 66]. Besides, a minority of mental or psychiatric conditions were included in the list. Furthermore, despite our relatively large sample size, some diseases were underrepresented, which might produce bias and decreasing statistical power. Another limitation is that disease duration has not been taken into account. Studies found worse HRQoL in specific diseases with longer disease duration, whilst other studies showed that longer disease duration was associated with better HRQoL [67]. Another limitation is that the EQ5D-5L covers relatively few dimensions of HRQoL that are disease-specific. The EQ-5D may therefore be insensitive to health problems (e.g. nausea, sleep disturbance) experienced by specific diseases [68]. Moreover, this study aimed for representativeness, hence the regression models were not corrected for several covariates (e.g. age, sex, educational attainment). A final limitation is the sampling procedure in the BHIS which can imply selection bias.

\section{Conclusions}

This study revealed that diverse multimorbidity patterns were synergistically or antagonistically associated with lower HRQoL. Given that multimorbidity will emerge in the coming decades, tackling its burden is needed, especially because most disease combinations affect each other synergistically, resulting in a greater reduction in HRQoL. Further knowledge about those combinations with a greater impact on HRQoL as well as knowledge on the complex relationship between HRQoL and multimorbidity is needed to better understand disease burden beyond mortality and morbidity data and to guide health care providers in their clinical practice and policy makers in their priority setting regarding multiple disease management decisions.

Supplementary Information The online version contains supplementary material available at https://doi.org/10.1007/ s11136-021-02951-w.

Author contributions DDS and LVW conceived the idea of this research. $\mathrm{EC}$ and $\mathrm{PB}$ have made substantial contribution to the design of the study. The analyses were performed by SDB, BD, and LVW. JVH, RC, DDB, and SV provided intellectual content. The first draft of the manuscript was written by LVW and all authors commented on previous versions of the manuscript. All authors read and approved the final manuscript.

Funding The organization of the BHIS was funded by the federal, regional, and community health authorities in Belgium. This study was funded by BOF (Bijzonder Onderzoeksfonds; Special Research Fund).

\section{Declarations}

Conflict of interest The authors declare that they have no competing interests.

Ethical approval The BHIS 2018 has been approved by the Privacy Commission and the Ethical Committee of the University Hospital of Ghent. 
Informed consent Informed consent was obtained from all individual participants included in the BHIS.

Open Access This article is licensed under a Creative Commons Attribution 4.0 International License, which permits use, sharing, adaptation, distribution and reproduction in any medium or format, as long as you give appropriate credit to the original author(s) and the source, provide a link to the Creative Commons licence, and indicate if changes were made. The images or other third party material in this article are included in the article's Creative Commons licence, unless indicated otherwise in a credit line to the material. If material is not included in the article's Creative Commons licence and your intended use is not permitted by statutory regulation or exceeds the permitted use, you will need to obtain permission directly from the copyright holder. To view a copy of this licence, visit http://creativecommons.org/licenses/by/4.0/.

\section{References}

1. Ock, M., Han, J. W., Lee, J. Y., Kim, S. H., \& Jo, M. W. (2015). Estimating quality-adjusted life-year loss due to noncommunicable diseases in Korean adults through to the year 2040. Value in Health: The Journal of the International Society for Pharmacoeconomics and Outcomes Research., 18(1), 61-66.

2. World Health Organization. (2018). Noncommunicable diseases. Available at https://www.who.int/en/news-room/fact-sheets/detail/ noncommunicable-diseases.

3. Barnett, K., Mercer, S. W., Norbury, M., Watt, G., Wyke, S., \& Guthrie, B. (2012). Epidemiology of multimorbidity and implications for health care, research, and medical education: A crosssectional study. The Lancet, 380(9836), 37-43.

4. Collaborators Global Burden of Disease. (2016). Global, regional, and national disability-adjusted life-years (DALYs) for 315 diseases and injuries and healthy life expectancy (HALE), 19902015: A systematic analysis for the Global Burden of Disease Study 2015. Lancet (London, England), 388(10053), 1603-1658.

5. Megari, K. (2013). Quality of life in chronic disease patients. Health Psychology Research, 1(3). https://doi.org/10.4081/hpr. 2013.e27.

6. Mar, J., Larranaga, I., Arrospide, A., \& Begiristain, J. M. (2010). Impact of disability on different domains of health-related quality of life in the noninstitutionalized general population. ClinicoEconomics and outcomes research: CEOR, 2, 97-103.

7. Schipper, H. C. J., \& Olweny, C. (1996). Quality of life studies: Definitions and conceptual issues. In B. Spilker (Ed.), Quality of life and pharmacoeconomics in clinical trials (pp. 11-23). Philadelphia: Lippincott-Raven Publishers.

8. Xu, R. H., Cheung, A. W. L., \& Wong, E. L. (2017). Examining the health-related quality of life using EQ-5D-5L in patients with four kinds of chronic diseases from specialist outpatient clinics in Hong Kong SAR, China. Patient Preference and Adherence, 11, $1565-1572$.

9. De Smedt, D., Clays, E., Annemans, L., Pardaens, S., Kotseva, K., \& De Bacquer, D. (2015). Self-reported health status in coronary heart disease patients: A comparison with the general population. European Journal of Cardiovascular Nursing: Journal of the Working Group on Cardiovascular Nursing of the European Society of Cardiology., 14(2), 117-125.

10. Jia, H., \& Lubetkin, E. I. (2016). Impact of nine chronic conditions for US adults aged 65 years and older: An application of a hybrid estimator of quality-adjusted life years throughout remainder of lifetime. Quality of Life Research, 25(8), 1921-1929.
11. Jia, H., Lubetkin, E. I., Barile, J. P., et al. (2018). Quality-adjusted life years (QALY) for 15 chronic conditions and combinations of conditions among US Adults Aged 65 and Older. Medical Care, 56(8), 740-746.

12. Park, S. J., Ahn, S., \& Park, K. H. (2016). Burden of visual impairment and chronic diseases. JAMA Ophthalmol, 134(7), 778-784.

13. Makovski, T. T., Schmitz, S., Zeegers, M. P., Stranges, S., \& van den Akker, M. (2019). Multimorbidity and quality of life: Systematic literature review and meta-analysis. Ageing Research Reviews, 53, 100903. https://doi.org/10.1016/j.arr.2019.04.005.

14. Sum, G., Salisbury, C., Koh, G. C. H., et al. (2019). Implications of multimorbidity patterns on health care utilisation and quality of life in middle-income countries: cross-sectional analysis. Journal of Global Health, 9(2). https://doi.org/10.7189/jogh.09.020413.

15. Fried, L. P., Bandeen-Roche, K., Kasper, J. D., \& Guralnik, J. M. (1999). Association of comorbidity with disability in older women: The Women's Health and Aging Study. Journal of Clinical Epidemiology, 52(1), 27-37.

16. Fultz, N. H., Ofstedal, M. B., Herzog, A. R., \& Wallace, R. B. (2003). Additive and interactive effects of comorbid physical and mental conditions on functional health. Journal of Aging and Health, 15(3), 465-481.

17. McDaid, O., Hanly, M. J., Richardson, K., Kee, F., Kenny, R. A., Savva, G. M. (2013). The effect of multiple chronic conditions on self-rated health, disability and quality of life among the older populations of Northern Ireland and the Republic of Ireland: A comparison of two nationally representative crosssectional surveys. BMJ Open, 3(6). https://doi.org/10.1136/bmjop en-2013-002571.

18. Pati, S., Swain, S., Knottnerus, J. A., Metsemakers, J. F., \& van den Akker, M. (2019). Health related quality of life in multimorbidity: A primary-care based study from Odisha, India. Health and Quality of Life Outcomes, 17(1), 116.

19. Fortin, M., Lapointe, L., Hudon, C., Vanasse, A., Ntetu, A. L., \& Maltais, D. (2004). Multimorbidity and quality of life in primary care: A systematic review. Health and Quality of life Outcomes, 2(1), 51.

20. Van Oyen, H., Tafforeau, J., Hermans, H., et al. (1997). The Belgian health interview survey. Archives of Public Health, 55, 1-13.

21. Herdman, M., Gudex, C., Lloyd, A., et al. (2011). Development and preliminary testing of the new five-level version of EQ-5D (EQ-5D-5L). Quality of Life Research, 20(10), 1727-1736.

22. Charafeddine, E. B. R., \& Van der Heyden, J. (2018). Gezondheidsenquête 2018: Gezondheidsgerelateerde kwaliteit van leven. Brussel, België. Rapportnummer: D/2019/14.440/37. Available at www.gezondheidsenquete.be.

23. Demarest, S., Van der Heyden, J., Charafeddine, R., Drieskens, S., Gisle, L., \& Tafforeau, J. (2013). Methodological basics and evolution of the Belgian health interview survey 1997-2008. Archives of Public Health, 71(1), 24.

24. World Health Organization. (2004). ICD-10: International statistical classification of diseases and related health problems: Tenth revision.

25. Fortin, M., Almirall, J., \& Nicholson, K. (2017). Development of a research tool to document self-reported chronic conditions in primary care. Journal of Comorbidity, 7(1), 117-123.

26. Boeckxstaens, P., \& Multimorbidity, P. M. (2020). Definition, assessment, measurement and impact. Encyclopedia of biomedical gerontology (pp. 455-460). Elsevier.

27. Thiry, N., Neyt, M., Van De Sande, S., Cleemput, I. (2014). Belgian guidelines for economic evaluations: Second edition. International Journal of Technology Assessment in Health Care, 30(6), 601-607. https://doi.org/10.1017/s0266462314000725.

28. Cleemput, I. (2010). A social preference valuations set for EQ-5D health states in Flanders, Belgium. The European Journal of 
Health Economics: HEPAC: Health Economics in Prevention and Care, 11(2), 205-213.

29. van Hout, B., Janssen, M. F., Feng, Y. S., et al. (2012). Interim scoring for the EQ-5D-5L: Mapping the EQ-5D-5L to EQ-5D-3L value sets. Value in health: The journal of the International Society for Pharmacoeconomics and Outcomes Research, 15(5), 708-715.

30. Charafeddine, R., Demarest, S., Cleemput, I., Van Oyen, H., \& Devleesschauwer, B. (2017). Gender and educational differences in the association between smoking and health-related quality of life in Belgium. Preventive Medicine, 105, 280-286.

31. Hunger, M., Thorand, B., Schunk, M., et al. (2011). Multimorbidity and health-related quality of life in the older population: Results from the German KORA-age study. Health and Quality of Life Outcomes, 9, 53

32. Mujica-Mota, R. E., Roberts, M., Abel, G., et al. (2015). Common patterns of morbidity and multi-morbidity and their impact on health-related quality of life: Evidence from a national survey. Quality of Life Research, 24(4), 909-918.

33. Arokiasamy, P., Uttamacharya, U., Jain, K., et al. (2015). The impact of multimorbidity on adult physical and mental health in low-and middle-income countries: What does the study on global ageing and adult health (SAGE) reveal? BMC medicine., 13(1), 178.

34. Van Wilder, L., De Smedt, D., Beutels, P., Cleemput, I., Bilcke, J., Speybroeck, N., Van der Heyden, J., Van Oyen, H., Charaffedine, R., \& Devleesschauwer, B. (2020). Belgian population norms for the EQ-5D-5L, 2013 and 2018. European Journal of Public Health, 30(Supplement_5), ckaa165-332.

35. Van Wilder, L., Rammant, E., Clays, E., Devleesschauwer, B., Pauwels, N., \& De Smedt, D. (2019). A comprehensive catalogue of EQ-5D scores in chronic disease: Results of a systematic review. Quality of Life Research, 28, 3153-3161. https://doi.org/ 10.1007/s11136-019-02300-y.

36. Fortin, M., Stewart, M., Poitras, M.-E., Almirall, J., \& Maddocks, H. (2012). A systematic review of prevalence studies on multimorbidity: Toward a more uniform methodology. The Annals of Family Medicine., 10(2), 142-151.

37. Gordon, J., Miller, G. C., \& Britt, H. (2018). What are chronic conditions that contribute to multimorbidity? Australian Journal of General Practice, 47(1-2), 20-23.

38. Fortin, M., Bravo, G., Hudon, C., Vanasse, A., \& Lapointe, L. (2005). Prevalence of multimorbidity among adults seen in family practice. The Annals of Family Medicine, 3(3), 223-228.

39. Van den Bussche, H., Koller, D., Kolonko, T., et al. (2011). Which chronic diseases and disease combinations are specific to multimorbidity in the elderly? Results of a claims data based crosssectional study in Germany. BMC Public Health, 11(1), 101.

40. Boeckxstaens, P., Peersman, W., Goubin, G., et al. (2014). A practice-based analysis of combinations of diseases in patients aged 65 or older in primary care. BMC Family Practice, 15, 159.

41. World Health Organization. Metrics: Disability-Adjusted Life Year (DALY). Available at https://www.hoint/healthinfo/global_ burden_disease/metrics_daly/en/.

42. Haagsma, J. A., van Beeck, E. F., Polinder, S., Toet, H., Panneman, M., \& Bonsel, G. J. (2011). The effect of comorbidity on health-related quality of life for injury patients in the first year following injury: Comparison of three comorbidity adjustment approaches. Population Health Metrics, 9(1), 10.

43. Rijken, M., Van Kerkhof, M., Dekker, J., \& Schellevis, F. G. (2005). Comorbidity of chronic diseases. Quality of Life Research., 14(1), 45-55.

44. Evans, D. L., Staab, J., Ward, H., et al. (1996). Depression in the medically ill: Management considerations. Depression and Anxiety, 4(4), 199-208.
45. Wee, H.-L., Cheung, Y.-B., Li, S.-C., Fong, K.-Y., \& Thumboo, J. (2005). The impact of diabetes mellitus and other chronic medical conditions on health-related quality of life: Is the whole greater than the sum of its parts? Health and Quality of Life Outcomes, $3(1), 2$.

46. Sprangers, M. A., \& Schwartz, C. E. (1999). Integrating response shift into health-related quality of life research: A theoretical model. Social Science \& Medicine, 48(11), 1507-1515. https:// doi.org/10.1016/s0277-9536(99)00045-3.

47. Wee, H. L., Cheung, Y. B., Li, S. C., Fong, K. Y., \& Thumboo, J. (2005). The impact of diabetes mellitus and other chronic medical conditions on health-related Quality of Life: Is the whole greater than the sum of its parts? Health and Quality of Life Outcomes, 3,2 .

48. Bouckaert, N., Gerkens, S., Devriese, S., \& Cleemput, I. (2021). An EQ-5D-5L value set for Belgium-How to value health-related quality of life? (p. 342). Brussels: Belgian Health Care Knowledge Centre (KCE).

49. Ben, Â., Finch, A. P., van Dongen, J. M., et al. (2020). Comparing the EQ-5D-5L crosswalks and value sets for England, the Netherlands and Spain: Exploring their impact on cost-utility results. Health Economics, 29(5), 640-651.

50. Alava, M. H., Wailoo, A., Grimm, S., et al. (2018). EQ-5D-5L versus EQ-5D-3L: The impact on cost effectiveness in the United Kingdom. Value in Health, 21(1), 49-56.

51. Mulhern, B., Feng, Y., Shah, K., et al. (2018). Comparing the UK EQ-5D-3L and English EQ-5D-5L value sets. PharmacoEconomics, 36(6), 699-713.

52. Brettschneider, C., Leicht, H., Bickel, H., et al. (2013). Relative impact of multimorbid chronic conditions on health-related quality of life-results from the MultiCare Cohort Study. PLoS ONE, 8(6), e66742.

53. Agborsangaya, C. B., Lahtinen, M., Cooke, T., \& Johnson, J. A. (2014). Comparing the EQ-5D 3L and 5L: Measurement properties and association with chronic conditions and multimorbidity in the general population. Health and Quality of Life Outcomes, 12,74 .

54. Lix, L. M., Yogendran, M. S., Shaw, S. Y., Targownick, L. E., Jones, J., \& Bataineh, O. (2010). Comparing administrative and survey data for ascertaining cases of irritable bowel syndrome: A population-based investigation. BMC Health Services Research, 10(1), 1-9.

55. Mittelmark, M. B., Psaty, B. M., Rautaharju, P. M., et al. (1993). Prevalence of cardiovascular diseases among older adults. The Cardiovascular Health Study. American Journal of Epidemiology, 137(3), 311-317. https://doi.org/10.1093/oxfordjournals.aje. a116678.

56. Martin, L. M., Leff, M., Calonge, N., Garrett, C., \& Nelson, D. E. (2000). Validation of self-reported chronic conditions and health services in a managed care population. American Journal of Preventive Medicine, 18(3), 215-218.

57. Jiang, L., Zhang, B., Smith, M. L., et al. (2015). Concordance between Self-reports and medicare claims among participants in a national study of chronic disease self-management program. Frontiers in Public Health, 3, 222.

58. Lix, L. M., Yogendran, M. S., Shaw, S. Y., Burchill, C., Metge, C., \& Bond, R. (2008). Population-based data sources for chronic disease surveillance. Chronic Diseases in Canada, 29(1), 31-38.

59. Muggah, E., Graves, E., Bennett, C., \& Manuel, D. G. (2013). Ascertainment of chronic diseases using population health data: A comparison of health administrative data and patient self-report. BMC Public Health, 13, 16.

60. Hansen, H., Schäfer, I., Schön, G., et al. (2014). Agreement between self-reported and general practitioner-reported chronic conditions among multimorbid patients in primary care-results of the MultiCare Cohort Study. BMC Family Practice, 15(1), 39. 
61. Kriegsman, D. M., Penninx, B. W., Van Eijk, J. T. M., Boeke, A. J. P., \& Deeg, D. J. (1996). Self-reports and general practitioner information on the presence of chronic diseases in community dwelling elderly: A study on the accuracy of patients' self-reports and on determinants of inaccuracy. Journal of clinical epidemiology., 49(12), 1407-1417.

62. Banks, J., Marmot, M., Oldfield, Z., \& Smith, J. P. (2006). Disease and disadvantage in the United States and in England. JAMA, 295(17), 2037-2045.

63. Skinner, K. M., Miller, D. R., Lincoln, E., Lee, A., \& Kazis, L. E. (2005). Concordance between respondent self-reports and medical records for chronic conditions: Experience from the Veterans Health Study. The Journal of ambulatory care management., 28(2), 102-110.

64. Selim, A. J., Fincke, G., Ren, X. S., et al. (2004). Comorbidity assessments based on patient report: Results from the Veterans Health Study. Journal of Ambulatory Care Management, 27(3), 281-295.

65. Hessmann, P., Seeberg, G., Reese, J. P., et al. (2016). Healthrelated quality of life in patients with Alzheimer's disease in different German health care settings. Journal of Alzheimer's disease: JAD., 51(2), 545-561.

66. Saarni, S. I., Suvisaari, J., Sintonen, H., Koskinen, S., Harkanen, T., \& Lonnqvist, J. (2007). The health-related quality-of-life impact of chronic conditions varied with age in general population. Journal of Clinical Epidemiology, 60(12), 1288-1297.

67. Busija, L., Tan, J., \& Sanders, K. M. (2017). Associations between illness duration and health-related quality of life in specified mental and physical chronic health conditions: Results from a population-based survey. Quality of Life Research., 26(10), 2671-2681.

68. Wailoo, A., Davis, S., \& Tosh, J. (2010). The incorporation of health benefits in cost utility analysis using the EQ-5D. School of Health and Related Research: University of Sheffield.

Publisher's Note Springer Nature remains neutral with regard to jurisdictional claims in published maps and institutional affiliations. 